\title{
Effects of Radiotherapy on Ehrlich's Ascetic Carcinoma in Swiss Albino Mice: An Experimental Study
}

\author{
Utpal Goswami ${ }^{1}$, Amit Kumar Verma ${ }^{2 *}$, Narshima Rao Banoth ${ }^{1}$, Anupam Brahma ${ }^{1}$, Sayandev Dasgupta ${ }^{3}$, \\ Saroj Krishna Bhattacharyya ${ }^{4}$
}

\begin{abstract}
Background: Experimental tumors have great importance in modeling, and Ehrlich ascites carcinoma (EAC) is one of the most common tumors. EAC is referred to as an undifferentiated carcinoma and is originally hyperdiploid, has high transplantable capability, no-regression, rapid proliferation, shorter life span, 100\% malignancy, and also does not have tumor-specific transplantation antigen. The current concepts that radiotherapy alone or with cancer chemotherapy is administered at a dose to the maximum a patient can tolerate before the onset of severe and even life-threatening toxicity is still in wide clinical use. This study was conducted to evaluate the response of radiotherapy in the treatment of EAC. Materials and Methods: A mouse bearing the tumor strain was taken from our laboratory in the Department of Pathology, IPGMER, Kolkata, where the strain was being maintained serially by inoculation of malignant cells into healthy mice every 8-10 days. In our work, altogether 25 mice were taken for each set of experimental work. They were divided in four groups of 5-10 mice in each group. The various parameters to assess the response of various therapeutic schedules were regression of tumor by decrease in body weight of mice and decrease in abdominal girth; cell count of ascetic fluid and morphological changes of tumor cells after treatment with drugs and to study the percentage viability of the cells. Results: All the mice in Group I gained weight steadily. Mice of Group II were unaffected by single dose whole body radiation and they behaved as mice of Group I. All mice of Group III died within 20-25 days. Conclusion: Cell changes were observed but not as marked. Cell viability was as high as $65 \%$ after treatment as compared to tumor control which showed a viability of about $75 \%$.
\end{abstract}

Keywords: Ehrlich's ascetic carcinoma, Swiss albino mice, Radiotherapy, Survival

Asian Pac. J. Health Sci., (2020); DOI: 10.21276/apjhs.2020.7.3.5

\section{INTRODUCTION}

Experimental tumors have great importance for the purposes of modeling, and Ehrlich ascites carcinoma (EAC) is one of the most common. ${ }^{[1]}$ It appeared first as a spontaneous breast cancer in a female mouse (Aktaş, 1996 ${ }^{[2]}$; Taşkin, 2002 ${ }^{[3]}$ ), and then Ehrlich and Apolant (1905) $)^{[4]}$ used it as an experimental tumor by transplanting tumor tissues subcutaneously from mouse to mouse.

In the early 1900s, the famous German chemist Paul Ehrlich set about developing drugs to treat infectious diseases. He was the one who coined the term "chemotherapy" and defined it as the use of chemicals to treat disease. He was also the first person to document the effectiveness of animal models to screen a series of chemicals for their potential activity against diseases, an accomplishment that had major ramifications for cancer drug development. In 1908, his use of the rabbit model for syphilis led to the development of arsenicals to treat this disease. Ehrlich was also interested in drugs to treat cancer, including aniline dyes and the first primitive alkylating agents, but apparently was not optimistic about the chance for success. ${ }^{[5]}$

For most primary tumors, the treatment of choice is surgery and radiotherapy, which measures can be very effective for controlling localized tumors and indeed surgery and radiotherapy dominated the field of cancer therapy into the 1960s. However, at the time of diagnosis, the majority of cancers have already microscopically metastasized throughout the body, leading to recurrent disease in the majority of cancer patients. Today, the various modes of therapy that is available for the treatment of cancers are surgery, chemotherapy, radiotherapy, endocrine therapy, and immunotherapy. Extensive surgery is probably one of the best modes of therapy if there is no metastasis. Chemotherapy and radiotherapy come next to
'Department of Pathology, ICARE Institute of Medical Sciences and Research, Banbishnupur, Purba Medinipur, Haldia, West Bengal, India, ${ }^{2}$ Department of Pharmacology, Shri Ramkrishna Institute of Medical Sciences, Kanksha, Durgapur, West Bengal, India, ${ }^{3}$ Department of General Surgery, ICARE Institute of Medical Sciences and Research, Banbishnupur, Purba Medinipur, Haldia, West Bengal, India, ${ }^{4}$ Department of Radiotherapy, ICARE Institute of Medical Sciences and Research, Banbishnupur, Purba Medinipur, Haldia, West Bengalm India Corresponding Author: Amit Kumar Verma, Department of Pharmacology, Shri Ramkrishna Institute of Medical Sciences, Malandighi, Kanksha Durgapur-713212, West Bengal, India. E-mail: amitkumarverma55@gmail.com

How to cite this article: Goswami U, Verma AK, Banoth NR, Brahma A, Dasgupta S, Bhattacharyya SK. Effects of Radiotherapy on Ehrlich's Ascetic Carcinoma in Swiss Albino Mice: An Experimental Study. Asian Pac. J. Health Sci., 2020; 7(3):18-22

Source of support: Nil

Conflicts of interest: None

Received: 12/12/2019 Revised:20/01/2020 Accepted:08/02/2020

surgery. The usefulness of one over the other depends on the type of cancer. ${ }^{[6]}$

Different tumor strains and different animals including rats, mice, and dogs have been used to assess the antitumor activity of a drug. Most of the antineoplastic drugs are having extensive adverse effects with efficacy and in high doses that limit the usefulness of any drugs except hormone. ${ }^{[7]}$

Tumor radiotherapy is a technique that is used to inhibit and control growth, metastasis, and proliferation of malignant tumor cells using various types of ionizing radiation. It needs no further explanation of the effects of radiation of cells since a great deal of 
it has been mentioned. This experiment was conducted to see the effect of only radiotherapy.

\section{Objectives}

This study was conducted to evaluate the response of radiotherapy in the treatment of EAC. The various parameters to assess the response of various therapeutic schedules were as follows:

1. To assess the regression of tumor by decrease in body weight of mice and decrease in abdominal girth.

2. To study the cell count of ascetic fluid after treatment with radiotherapy.

3. To study morphological changes of tumor cells after subjecting it to antineoplastic drug.

4. To study the percentage viability of the cells.

5. To study the animal survival.

\section{Materials and Methods}

Transplantation of EAC in mice (ascetic form): The proliferation of malignant cells of the EAC strain simulates the biology of any neoplasia. Hence, this study forms a tumor model on which different anti-neoplastic agents have been tried to study the kind of therapy which would form the best mode of treatment.

\section{Tumor Strain}

A mouse bearing the tumor strain was taken from our laboratory in the Department of Pathology, IPGMER, Kolkata, where the strain was being maintained serially by inoculation of malignant cells into healthy mice every $8-10$ days. The mouse that was taken had a huge ascites from which cells were taken to inoculate mice further. Male Swiss albino mice weighing about 16-18 gm were chosen for our study.

\section{Transplantation}

At first a preliminary diagnosis was made regarding the presence of ascites in the mice by noting the gain in weight; gain in abdominal girth and by palpating the abdomen. Then with the help of a sterile tuberculin syringe and a needle of 21 gauge, $0.5 \mathrm{ml}$ sterile normal saline was taken and peritoneal cavity was punctured. This $0.5 \mathrm{ml}$ sterile normal saline was then pushed into the peritoneal cavity to dilute the cell suspension in the immediate vicinity of the needle and to separate any fibrin coagulum if formed so that the cell suspension could flow out freely. Sample with whitish fluid was taken in the syringe. This was then diluted 1:10 in sterile physiological saline. A drop from this suspension was taken and changed in the Neubauer's hemocytometer. A cell count was done under the optical microscope. The cell suspension was again diluted in sterile normal saline to obtain a desired cell suspension of about $10^{7}$ cells $/ \mathrm{ml}$.

Simultaneously $0.02 \mathrm{ml}$ cell suspension was taken, diluted in the ratio of $1: 10$ in $0.15 \%$ trypan blue made up in physiological saline. A drop of cell suspension was taken and a coverslip preparation was made to study the viability of the cells. The viable cells did not take up any stain whereas the dead cells were stained blue. The percentage of viable cells was noted down.

The slides made out from smears of centrifuged deposit were stained by hematoxylin and eosine which showed large malignant cells with hyperchromatic nuclei with nucleoli and scanty cytoplasm [Figure 1]. After having confirmed the presence of malignant cells, the suspension was used to inoculate the mice. About $0.1 \mathrm{ml}$ of prepared suspension was then taken and diluted in $0.4 \mathrm{ml}$ of sterile normal saline and this mixture $(0.5 \mathrm{ml})$ was inoculated into each mouse intraperitoneally. Thus, the desired cell concentration of $10^{6}$ cells per inoculums dose was obtained. The mice were maintained on pellets prepared by Hindustan Lever Company and water ad libitum. The weight of individual mice with their abdominal girth was noted before starting the experiment.

\section{Animal Grouping}

In our work, altogether 25 healthy mice weighing about 16-18 gm were taken. Of them 15 were used to transplant the tumor in them. Confirmation of tumor "cells uptake" was done after 7 days by aspirating some peritoneal fluid aseptically and examining a stained deposit under optical microscope. Once confirmation was done that the therapeutic regime was designed and the animals were grouped as follows. They were divided into four groups of 5-10 mice in each group.

- Group I: Five healthy mice which were maintained on feed and water only. These served as healthy controls.

- $\quad$ Group II: Five mice who were given who were given a single dose of whole body radiation of 400 rads.

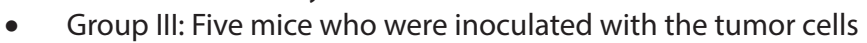
and left as such without any treatment. These served as tumor controls.

- Group IV: Ten tumors bearing mice on whom single whole body radiation was given.

\section{Methods of Observations}

Each mouse was weighed in grams before transplantation of tumor strain; before starting treatment and 5 days after the end of treatment. Abdominal girth of each mouse was taken in centimeters in the same schedule as above. The effect of therapy was recorded according to the protocol laid by Sugiura (1961). ${ }^{[8]}$

- $\quad[+++]$ Indicates complete inhibition or diminution of ascites.

- $[++]$ Marked inhibition indicating no abdominal distension, no gross ascites.

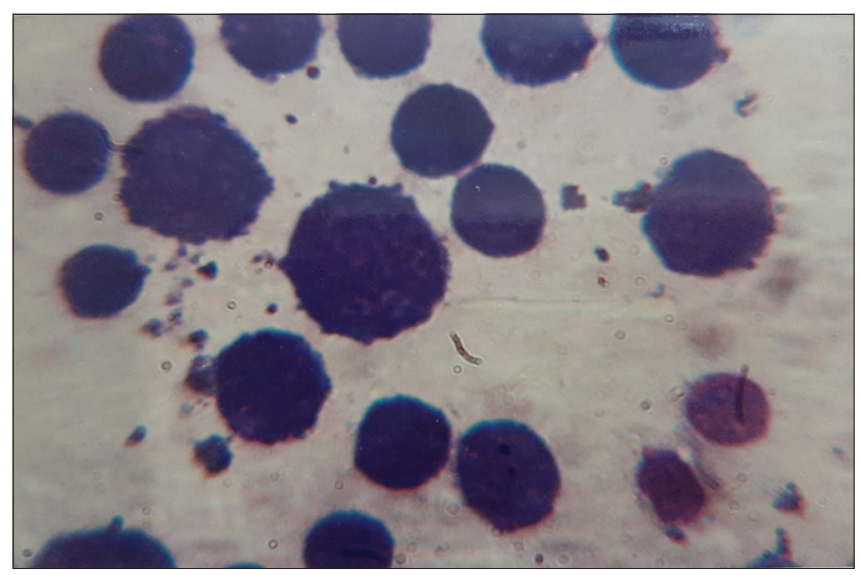

Figure 1: A hematoxylin and eosine stained smear of centrifuged deposit of peritoneal fluid. Malignant cells like large cells with hyperchromatic nuclei with a very thin rim of basophilic cytoplasm $(\times 400)$ confirming successful uptake of tumor cells before starting treatment with radiotherapy 
- $\quad[+]$ Moderate inhibition indicating slight distension; the fluid volume increased only up to $1 / 4$ of the volume increased only up to $1 / 4$ of the volume of the tumor control.

- $[ \pm]$ Slight inhibition indicating moderate abdominal distension, the fluid volume increased up to $1 / 2$ of the volume of the tumor control.

- $\quad[-]$ No effect, indicating marked abdominal distension, the fluid volume increased up to $3 / 4$ or more of the volume of the tumor control.

Survival time of each mouse was noted in relation to the life of healthy and drug control mice. In case of any death of any mouse a postmortem was carried out to find out the cause of death. Tissues from lung, liver, and kidneys were taken and were fixed in $10 \%$ formalin solution. Tissues were processed as usual and paraffin sections were made and stained with hematoxylin and eosine. Each set of experiment was done twice.

\section{Confirmation of Successful Transplantation}

After about 5-7 days of inoculation any gain in weight and abdominal girth was noted. By careful palpation, it was seen that the abdomen showed evidence of fluid collection. A peritoneal tap was done carefully in an aseptic manner and the fluid obtained from the peritoneum was simultaneously diluted in normal saline to give a 1:20 dilution. This fluid was seen under the optical microscope in a Neubauer chamber. A cell count was done and recorded.

A centrifuged deposit of the cell suspension was taken and stained with hematoxylin and eosin [Figures 1-4]. The presence of large cells with hyperchromatic nuclei, nucleoli, and a thin rim of basophilic cytoplasm confirmed the presence of malignant cells in the peritoneal fluid. Immediately, a viable count was done and it was seen that about $90-95 \%$ cells were viable.

\section{Results}

All the mice in Group I gained weight steadily. Mice of Group II were unaffected by single dose whole body radiation and they behaved as mice of Group I. All mice of Group III died within 20-25 days. Group IV mice showed that the features are shown in Table 1.

All the healthy mice gained in weight and abdominal girth. The drug control mice lost some weight. After the treatment, morphological features of aspirated cells in smear stained in hematoxylin and eosine showed the following features: Degeneration of cells marked by vacuolation of cytoplasm; there is diminution in size of the nucleus; and the nuclear cytoplasmic ratio had diminished [Figures 3 and 4].

This mode of therapy was least effective as compared to others given except the triple therapy consisting of actinomycin D, mitomycin C, and radiotherapy. Cell viability was as high as $65 \%$ after treatment as compared to the tumor control which showed a viability of about $75 \%$.

\section{Discussion}

Anticancer therapy was based and still relies almost exclusively on surgical therapy, although associated therapy has developed over the past decades: Surgery and/or chemotherapy and/ or radiotherapy, with the development of cryotherapy, immunotherapy and in general, the adoption of techniques and methodologies used in human oncology. ${ }^{[7]}$

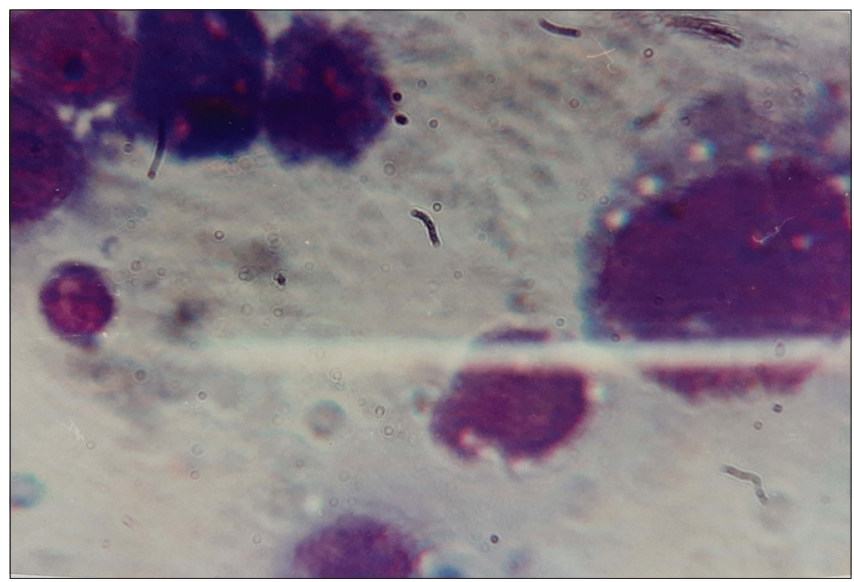

Figure 2: Cell morphology after treatment with radiotherapy $(\times 400)$

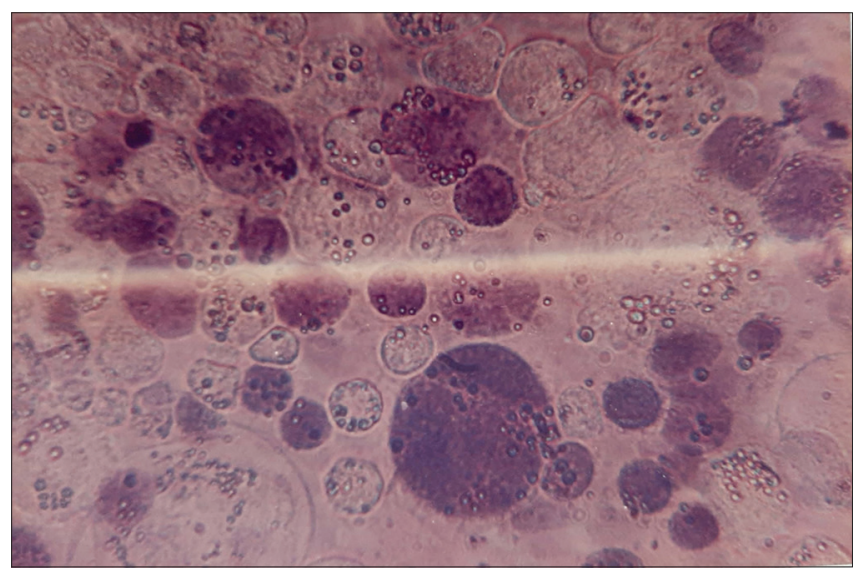

Figure 3: Cell viability count $2 \mathrm{~h}$ after incubation at $37^{\circ} \mathrm{C}$ following treatment with radiotherapy $(\times 160)$

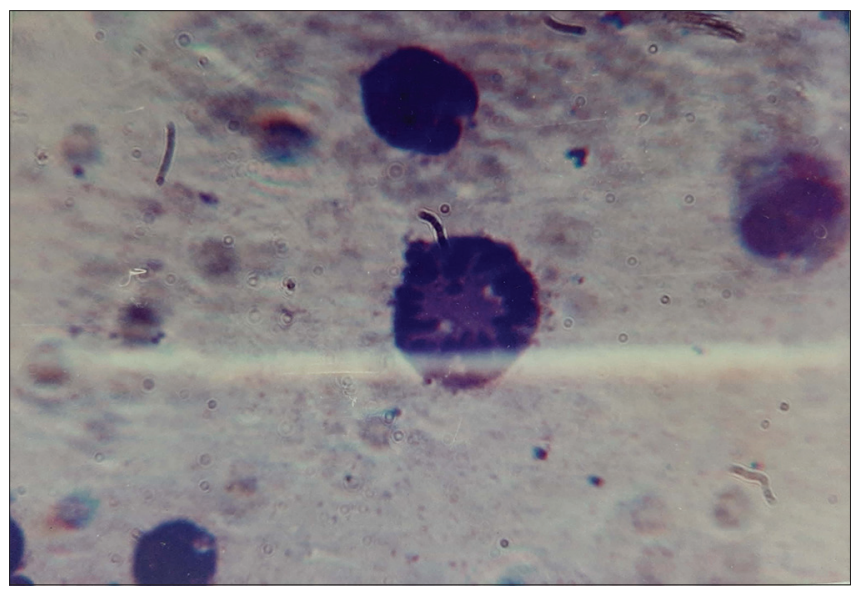

Figure 4: A cell showing karyorrhexis after treatment with radiotherapy $(\times 400)$

The therapeutic strategy should take into consideration three indispensable elements: $:^{[7]}$

- The histological nature of the lesion;

- The assessment of the extension of the tumor process;

- The evaluation of the general disease state. 
Table 1: Effect of radiotherapy on Ehrlich's ascetic carcinoma in mice

\begin{tabular}{|c|c|c|c|c|c|c|c|c|}
\hline \multirow[t]{2}{*}{ Groups } & \multicolumn{4}{|c|}{ Before therapy: After 7 days of tumor cell inoculation } & \multicolumn{4}{|c|}{ After therapy: 5 days after cessation of therapy } \\
\hline & $\begin{array}{l}\text { Avg. Wt. of } \\
\text { mice (gms.) }\end{array}$ & $\begin{array}{l}\text { Avg. Abdom. } \\
\text { Girth }(\mathrm{cm})\end{array}$ & $\begin{array}{l}\text { Avg. Cell count } \\
\text { (per } \mathrm{cmm})\end{array}$ & $\begin{array}{l}\text { Cell surviving } \\
\text { after } 2 \mathrm{~h}(\%)\end{array}$ & $\begin{array}{l}\text { Avg. Wt. of } \\
\text { mice (gm) }\end{array}$ & $\begin{array}{l}\text { Avg. Abdom. } \\
\text { Girth }(\mathrm{cm})\end{array}$ & $\begin{array}{l}\text { Avg. Cell count } \\
\text { (per } \mathrm{cmm} \text { ) }\end{array}$ & $\begin{array}{l}\text { Cell surviving } \\
\text { after } 2 \mathrm{~h}(\%)\end{array}$ \\
\hline I & 17 & 5.8 & Nil & $\mathrm{Nil}$ & 18 & 6.1 & Nil & $\mathrm{Nil}$ \\
\hline II & 17 & 6 & Nil & Nil & 16.5 & 6 & Nil & Nil \\
\hline III & 22 & 7.5 & $4 \times 10^{5}$ & 80 & 30 & 12 & $8 \times 10^{7}$ & 75 \\
\hline IV & 22 & 7.6 & $4 \times 10^{5}$ & 80 & 29 & 10 & $10^{6}$ & 65 \\
\hline
\end{tabular}

Ehrlich-Lettre ascites carcinoma (EAC) is also known as Ehrlich cell. It was originally established as an ascites tumor in mice. The tumor was cultured in vivo, which became known as the Ehrlich cell. After 1948, Ehrlich cultures spread around research institutes all over the world. The Ehrlich cell became popular because it could be expanded by in vivo passage. This made it useful for biochemical studies involving large amounts of tissues. It could also be maintained in vitro for more carefully controlled studies. Culture techniques in large-scale, mice passage are less attractive, due to the contamination of the tumor with multifarious host inflammatory cells. EAC is referred to as undifferentiated carcinoma and is originally hyper-diploid. The permeability to water is highest at the initiation of the $S$ phase and progressively decreases to its lowest value just after mitosis. Activation heats for water permeability vary during the cell cycle, ranging from 9-14 kca/mole. ${ }^{[9]}$

EAC is referred to as an undifferentiated carcinoma, and is originally hyperdiploid, has high transplantable capability, no-regression, rapid proliferation, shorter life span, 100\% malignancy, and also does not have tumor-specific transplantation antigen (Kaleoğlu and İşli, 1977). ${ }^{[10]}$

EAC has a resemblance with human tumors which are the most sensitive to chemotherapy due to the fact that it is undifferentiated and that it has a rapid growth rate. The examination of a stained smear by hematoxylin and eosins showed vacuolation of cytoplasm. The nucleus had become compact. The cytoplasm stained an eosinophilic tinge. If compared with the control, it can be said that the treatment group showed features of cellular degeneration. As we all know, radiation has several effects such as breaking of hydrogen bonds, formation of cross linkage between adjacent strands or closely apposed regions of the same strand, and impairment of the ability of DNA to act as a template for synthesis of new DNA strand. ${ }^{[1]}$

By 2040, 27.5 million new cases of malignancy are expected annually if the current prevalence of cancer and global population continue to grow at the same rate. ${ }^{[12]}$ In many types of cancer, ascites is a prognostic indication of advanced stage; just of cancer patients who are diagnosed with ascites live beyond a further 6 months. ${ }^{[13]}$ Combination therapy has become the base of cancer therapy. ${ }^{[14]}$ Fundamentally, the combined agents work in a synergistic or additive manner, and thus, the required therapeutic dose of each agent is low. ${ }^{[15]}$ The treatment with multiple agents enhances the possibility to target all cancer cells including cancer stem cells that are responsible for drug resistance and cancer recurrence. ${ }^{[16,17]}$

During tumor treatment, radiation is considered to be a "double-edged sword" because it not only affects the proliferation, metastasis, and other biological processes of neoplasms, but may also genetically modify normal tissues, causing damage to nontumor cells, which is a detrimental effect on the body that we do not expect. Conventionally, it has been revealed that irradiation can directly affect malignant cells by affecting DNA structure stability and repair processes, triggering DNA double-strand breaks and inducing therapeutic effects against tumor cells, such as apoptosis, necrosis, senescence, and abnormal mitosis. ${ }^{[18-20]}$ The latest research has shown that irradiation not only disturbs the structure of neoplasm cells such as the cell membrane and organelles but also interferes with cell signal transduction and regulation, changing neoplasm cells immunogenicity, and their microenvironment. ${ }^{[21,22]}$ Mouse studies of radiation effects on tumor biology have increased the field knowledge about the effect on the tumor microenvironment, including cytokine and immune cell response to radiation which affects the overall tumor response. ${ }^{[23,24]}$

\section{Conclusion}

Radiotherapy alone had the least damaging effect on the Ehrlich's ascetic tumor cells. Such therapeutic responses may also be found in human neoplasia of various kinds, since the biology of neoplasia remains the same everywhere. Research on the impact and the specific mechanism of radiation on tumors has become a central topic in cancer therapy.

\section{References}

1. Ehrlich $\mathrm{P}, \mathrm{Apolant} \mathrm{H}$. Beobachtungen uber maligne mausetumoren. Berl Klin Wschr 1905;28:871-4.

2. DeVita VT Jr., Chu E. A history of cancer chemotherapy. Cancer Res 2008;68:8643-53.

3. Arruebo M, Vilaboa N, Sáez-Gutierrez B, Lambea J, Tres A, Valladares M, et al. Assessment of the evolution of cancer treatment therapies. Cancers (Basel) 2011;3:3279-330.

4. Baba Al, Câtoi C. Principles of anticancer therapy. In: Comparative Oncology. Ch. 19. Bucharest, RO: The Publishing House of the Romanian Academy; 2007.

5. Sugiura K, Schmid FA, Schmid MM. Antitumor activity of cytoxan. Cancer Res 1961;21:1412-20.

6. DuPre AM, Hempling HG. Osmotic properties of Ehrlich ascites tumor cells during the cell cycle. J Cell Physiol 1978;97:381-96.

7. Kaleoğlu Ö, İşli N. Ehrlich-Lettre Asit Tümörü. Vol. 40. Tıp Fakültesi Mecmuası; 1977. p. 978-84.

8. Allen E, Alexander P. An effect of ionizing radiations on the hydrogen bonds in wool. Radiat Res 1961;15:390-9.

9. Bray F, Ferlay J, Soerjomataram I, Siegel RL, Torre LA, Jemal A. Global cancer statistics 2018: Globocan estimates of incidence and mortality worldwide for 36 cancers in 185 countries. CA Cancer J Clin 2018;68:394-424.

10. Parsons SL, Lang MW, Steele RJ. Malignant ascites: A 2-year review from a teaching hospital. Eur J Surg Oncol 1996;22:237-9.

11. Yap TA, Omlin A, de Bono JS. Development of therapeutic combinations targeting major cancer signaling pathways. J Clin Oncol 2013;31:1592-605.

12. Albain KS, Nag SM, Calderillo-Ruiz G, Jordaan JP, Llombart AC, Pluzanska $A$, et al. Gemcitabine plus paclitaxel versus paclitaxel 
monotherapy in patients with metastatic breast cancer and prior anthracycline treatment. J Clin Oncol 2008;26:3950-7.

13. Wang T, Narayanaswamy R, Ren H, Torchilin VP. Combination therapy targeting both cancer stem-like cells and bulk tumor cells for improved efficacy of breast cancer treatment. Cancer Biol Ther 2016;17:698-707.

14. Elkhawaga OA, Gebril S, Salah N. Evaluation of anti-tumor activity of metformin against Ehrlich ascites carcinoma in Swiss albino mice. Egypt J Basic Appl Sci 2019;6:116-23.

15. Wang J, Wang $\mathrm{H}$, Qian $\mathrm{H}$. Biological effects of radiation on cancer cells. Military Med Res 2018;5:20.

16. Denis V, Couturier AM, Tedim FM, Amélie R, Poirier GG, Fabrice F, et al. DNA damage signalling and repair inhibitors: The long-sought-after Achilles' heel of cancer. Biomol Ther 2015;5:3204-59.

17. Lewanski CR, Gullick WJ. Radiotherapy and cellular signalling. Lancet Oncol 2001;2:366-70.

18. Edimecheva IP, Kisel MA, Shadyro Ol, Vlasov AP, Yurkova IL. The damage to phospholipids caused by free radical attack on glycerol and sphingosine backbone. Int J Radiat Biol 1997;71:555-60.

19. Shao C, Folkard M, Michael BD, Prise KM. Targeted cytoplasmic irradiation induces bystander responses. Proc Natl Acad Sci U S A 2004;101:13495-500.

20. Bentzen SM. Preventing or reducing late side effects of radiation therapy: Radiobiology meets molecular pathology. Nat Rev Cancer 2006;6:702-13.

21. Koontz BF, Verhaegen F, De Ruysscher D. Tumour and normal tissue radiobiology in mouse models: How close are mice to mini-humans? Br J Radiol 2017;90:20160441.

22. Arnold KM, Flynn NJ, Raben A, Romak L, Yu Y, Adam P, et al. The impact of radiation on the tumor microenvironment: Effect of dose and fractionation schedules. Cancer Growth Metastasis 2018;11:1179064418761639.

23. Rivina L, Davoren MJ, Schiestl RH. Mouse models for radiationinduced cancers. Mutagenesis 2016;31:491-509.

24. Carvalho HA, Villar RC. Radiotherapy and immune response: The systemic effects of a local treatment. Clinics (Sao Paulo) 2018;73 Suppl 1:e557s. 